\title{
Recurrent Bleeding Neck Mass: a Case Report
}

\author{
Purushottam Chavan $^{1} \cdot$ Sreelekha Ray $^{1} \cdot$ Suma Sheshadri $^{2} \cdot$ Rajshekar Halkud $^{1}$
}

Received: 16 March 2017 / Accepted: 31 July 2017 /Published online: 23 August 2017

(C) Indian Association of Surgical Oncology 2017

\begin{abstract}
An adult male presented to us with a recurrent, large bleeding tumour in the neck. We describe our approach to the patient, whose tumour was labelled as an atypical glomus on final histopathology. They are relatively uncommon in the head neck, and this case report with literature review is expected to add to our knowledge.
\end{abstract}

Keywords Extradigital glomus · Atypical glomus

\section{Introduction}

We present a bleeding recurrent tumour in an adult male arising from the superficial soft tissues of the neck which grew to large proportions and diagnosed on histopathology as an atypical glomus. Documented accounts of treatment of atypical glomus are limited, and therefore, this report is expected to add to our knowledge.

\section{Case Report}

A 33-year-old male presented with a neck swelling, which had recurred after four surgeries over the past 8 years. The swelling was a $20 \times 10 \mathrm{~cm}$, soft, poorly compressible, non-pulastile boggy mass, with a diffusely bleeding ulcerated surface,

Sreelekha Ray

drlekhadey@gmail.com

1 Department of Head Neck Oncology, Kidwai Memorial Institute of Oncology, Dr MH Marigowda Road, Bangalore 560029, India

2 Department of Pathology, Kidwai Memorial Institute of Oncology, Dr MH Marigowda Road, Bangalore 560029, India arising from a sessile base from the entire right side of neck Fig. 1a.

A CECT of the neck was performed on an urgent basis Fig. 1b. With the provisional diagnosis of myopericytoma, based on the histopathology report of the previous operating institution, emergency surgery was performed. A circumlesional incision, starting at the anteroinferior quadrant was made, to gain control of the lower end of IJV, which was dissected upwards with the sternocleidomastoid muscle. The tumour was extremely vascular, with numerous varying calibre feeding vessels. It was attached to, and arising from the skin and soft tissues, in a plane superficial to the strap muscles, the carotid sheath and prevertebral muscles. The superior thyroid artery was ligated, and the external carotid artery was temporarily clamped distal to it Fig. 1c. The haemostasis improved dramatically, and specimen removal was done following the principles of radical neck dissection. The defect was reconstructed with a pectoralis major myocutaneous flap Fig. $1 \mathrm{~d}$. Apart from wound healing problems, requiring secondary suturing of primary site and repeat skin grafting of donor site, the patient had an uneventful recovery. He is doing well 1 year post treatment Fig. 1e and f.

The histopathological report and immunohistochemistry suggested the diagnosis of "glomus tumour of uncertain malignant potential" Fig. 2. Our tumour board advised adjuvant radiation on basis of size of tumour, multiple recurrences, time to recurrence, close surgical margins and mitotic figures of 10/ $10 \mathrm{hpf}$. Chemotherapy in the form of antiangiogenic therapy was held in reserve for the unlikely event of distant metastasis.

\section{Discussion}

Glomus tumours are neoplasms of the perivasculature involved in thermoregulation, not to be confused with 

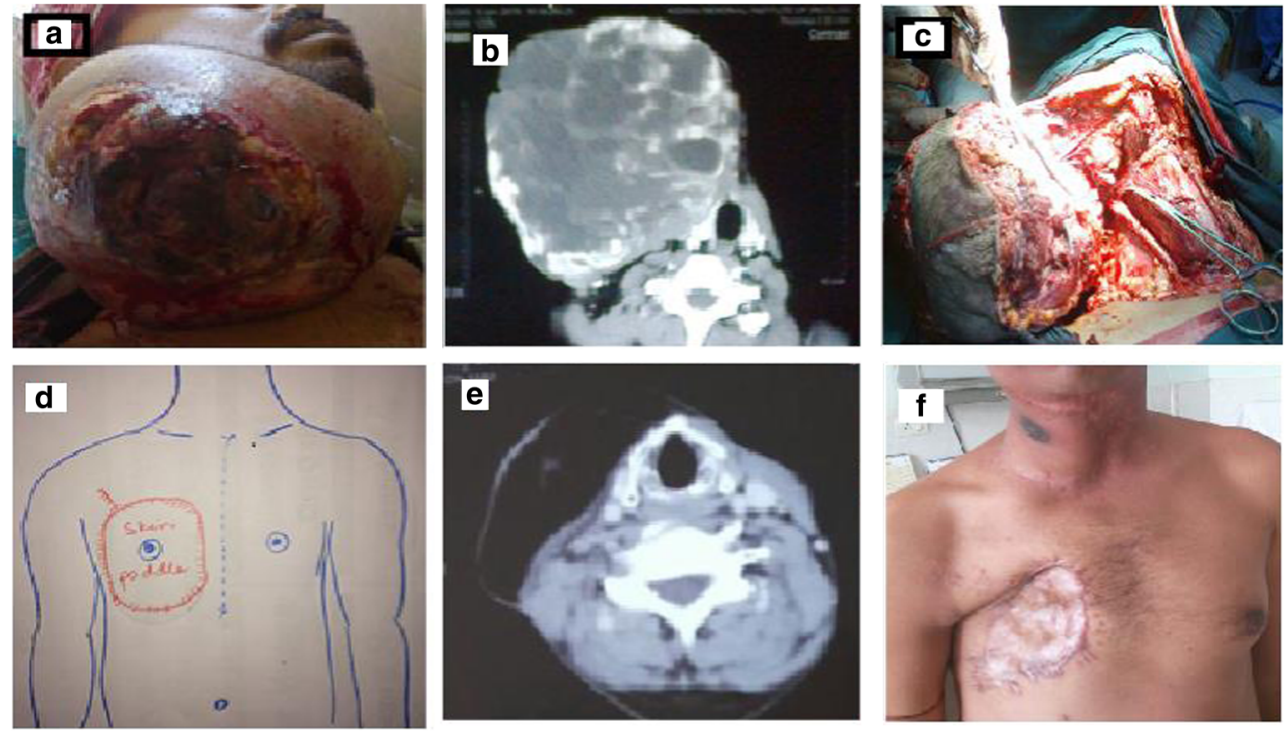

Fig. 1 a The neck swelling was $20 \times 10 \mathrm{~cm}$, poorly compressible, nonpulsatile boggy mass, with a diffusely bleeding, ulcerated surface, arising from a sessile base from the entire right side of neck. b CECT of the neck showed a well-delineated heterogenously enhancing vascular lesion with dilated vessels supplied by external carotid. The deeper structures appeared normal. c Intraoperative picture showing clamp on external

carotid artery. d PMMC markings-our myocutaneous flap was designed with the skin paddle around the nipple, instead of inferior and medial to it, keeping in mind the dimensions of the defect. e CECT neck done 1 year after surgery and RT does not show any recurrence. $\mathbf{f}$ Clinically, at 1-year follow-up, well-healed primary and donor sites

tumours of glomus cell, which is a chemoreceptor found in the carotid and aortic bodies.

Glomus tumours account for less than $2 \%$ of soft tissue tumours [1] located most commonly in the subungal regions, but extradigital sites including the bone, tongue, gastrointestinal tract, liver, mesentery, lung, bronchus, mediastinum, bladder, sacrum, coccyx, and head neck region $[2,3]$ have been described. Among head neck region, the sites are ear lobe, lips, facial, nasal and laryngeal

glomus tumours. Glomus tumours displaying unusual features, such as large size, deep location, infiltrative growth, mitotic activity, nuclear pleomorphism and necrosis have been subcategorised by Folpe [4].

Our case was classified as "glomus tumour of uncertain malignant potential" (synonymous with "atypical" glomus tumours) based on the features of possessing high mitotic activity (> 5/50 HPF) and a superficial location only, or large size only, or deep location only, and lacking the features of a

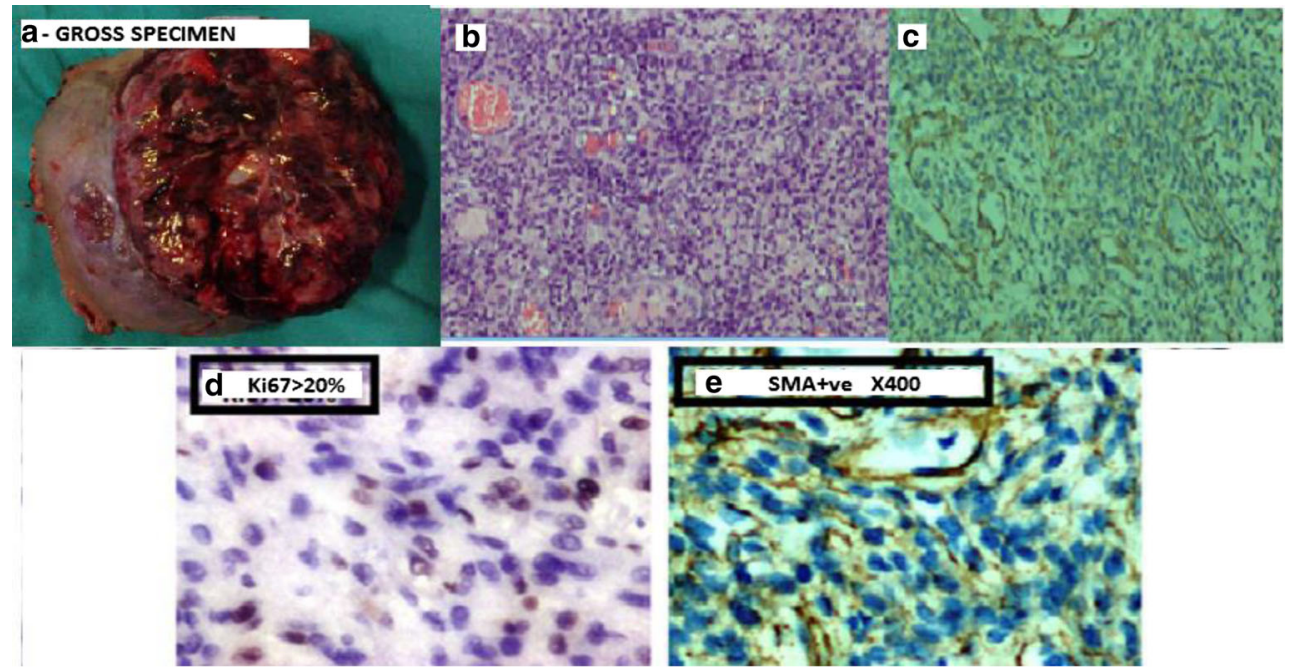

Fig. 2 a Gross specimen measured $22 \times 19 \times 10 \mathrm{~cm}$ with areas of necrosis. The cystic spaces varied in size from 0.5 to $1 \mathrm{~cm}$. b Sections showed hypo- and hypercellular areas. The cells are arranged in perivascular pattern and in sheets displaying mild nuclear pleomorphism. Mitosis amounts to $10 / 10 \mathrm{hpf}$. $(\mathrm{H} \& \mathrm{E} \times 100)$. c The cells

were positive for SMA with Ki67 index $>20 \%$. They were negative for CD34, CD31, and desmin. (Slide showing onlySMA positivity). d Sections showing Ki67 positivity $>20 \%$. $\times 400$ magnification showing SMA positivity 
Table 1 Classification of atypical glomus tumours: (Folpe et al.). Atypical glomus tumour: Glomus tumours display unusual features, such as large size, deep location, infiltrative growth, mitotic activity, nuclear pleomorphism, and necrosis. Atypical features are usually observed centrally with a rim of benign-appearing glomus tumour

\begin{tabular}{|c|c|c|c|}
\hline Malignant & Symplastic & $\begin{array}{l}\text { Glomus tumours of uncertain } \\
\text { malignant potential }\end{array}$ & Glomangiomatosis \\
\hline $\begin{array}{l}\text { Tumour with a deep location } \\
\text { and a size of more than } 2 \mathrm{~cm} \text {, or } \\
\text { atypical mitotic figures, or moderate to } \\
\text { high nuclear grade and } 5 \text { mitotic } \\
\text { figures or more than } 50 \mathrm{HPF}\end{array}$ & $\begin{array}{l}\text { High nuclear grade in the absence } \\
\text { other malignant features. } \\
\text { (High nuclear grade alone, } \\
\text { infiltrative growth, and vascular } \\
\text { space involvement are not } \\
\text { associated with metastasis) }\end{array}$ & $\begin{array}{l}\text { Tumours that lack criteria for malignant } \\
\text { glomus tumour or symplastic glomus } \\
\text { tumour but have high mitotic activity and } \\
\text { superficial location only or large size only } \\
\text { or deep location only. }\end{array}$ & $\begin{array}{l}\text { Tumours with histologic } \\
\text { features of diffuse } \\
\text { angiomatosis and } \\
\text { excess glomus cells. }\end{array}$ \\
\hline
\end{tabular}

malignant glomus [4]. Tumour with a deep location and a size of more than $2 \mathrm{~cm}$, or atypical mitotic figures, or moderate to high nuclear grade and 5 mitotic figures or more/50 HPF are classified as malignant glomus tumour (Table 1).

In contrast to typical glomus which are benign, small, solitary, purplish firm lesions with classic triad of pain, localised tenderness, and cold hypersensitivity, extradigital tumours have a lower incidence of pain and cold intolerance, and a greater frequency of glomangioma subtype [5]. Some glomus tumours, especially in the head neck regions reach large proportions, causing sagging of the cheek, lips, chin and areas of soft tissue they arise from, as is seen in our patient. Ultrasonography is a useful non-invasive method, but MRI is the most sensitive imaging modality for the diagnosis of glomus tumours [6] as gadolinium enhancement offers differential features with common vascular malformations. CECT is a rapid means of delineating the deeper anatomic structures for operative management. Because of their subcutaneous location and indolent nature, glomus tumours are amenable to complete removal. Surgical resection is therefore the definitive treatment [7]. Postsurgical recurrence rate of glomus tumour is approximately $10 \%$, and malignant transformation after recurrence or dedifferentiation can occur [8]. There is little data on role of adjuvant treatment.

\section{Conclusion}

Glomus tumours are rare and pose a challenge for the surgeon and the histopathologist alike; therefore, misdiagnosis is common. Improved guidelines regarding symptoms, diagnosis and treatment of these neoplasms may reduce the morbidity for the patient.

\section{References}

1. Zhang Y, Li H, Zhang WQ (2013) Malignant glomus tumor of the esophagus with mediastinal lymph node metastases. Ann Thorac Surg 96:1464-1466

2. Kale SS, Rao VK, Bentz ML (2006) Glomus tumor of the index finger. J Craniofac Surg 17:801-804 View Article : Google Scholar : PubMed/NCBI

3. Enzinger FM, Weiss SW (2001) Perivascular tumors. Enzinger and Weiss's Soft tissue tumors, 4th edn. Mosby, Maryland Heights, pp 985-1035

4. Folpe AL, Fanburg-Smith JC, Miettinen M, Weiss SW (2001) Atypical and malignant glomus tumors: analysis of 52 cases, with a proposal for the reclassification of glomus tumors. Am J Surg Pathol 25:1-12

5. Lee D-W, Yang J-H, Chang S, Won C-H, Lee M-W, Choi J-H, Moon $\mathrm{K}-\mathrm{C}$ Clinical and pathological characteristics of extradigital and digital glomus tumours: a retrospective comparative study. J Eur Acad Dermatol Venereol 25:1392-1397. doi:10.1111/j.1468-3083.2011. 03979.x

6. Al- Qattan MM, Al-Namla A, Al-Thunayan A, Al-Subhi F, AlShayeb AF (2005) Magnetic resonance imaging in the diagnosis of glomus tumours of the hand. J Hand Surg Eur Vol 30(5):535-554. doi:10.1016/j.jhsb.2005.06.009

7. Veros K, Markou K, Filitatzi C, Kyrmizakis DE (2012) Glomus tumor of the cheek: a case report. Case Rep Med; Article ID 307294, 3 pages, 2012. doi:10.1155/2012/307294

8. Gombos Z, Zhang PJ (2008) Glomus tumor. Arch Pathol Lab Med 132(9):1448-1452 